\title{
ON A PECULIARITY IN THE COURSE OF CERTAIN STREAMS IN THE LONDON AND HAMPSHIRE BASINS.
}

By H. J. OSBORNE WHITE, F.G.S.

(Read fune 6th, 1903).

I.

THOSE who have examined the details of the hydrography of south-eastern England cannot have failed to notice that, while the streams which drain the northern and southern slopes of the topographical depressions marking the geological basins of London and Hampshire normally pursue tolerably rectilinear paths from their sources down to their junctions with the principal west-to-east rivers following the longitudinal axes of these depressions, there are some which undergo an abrupt change of direction, whereby their lower parts assume a course roughly at right angles to that of their upper parts, and sensibly parallel to that of their appropriate main-stream. As this change of route on the part of a northerly or southerly tributary invariably takes the form of a turn in the direction towards which the adjoining section of the main stream flows, it results in the two rivers uniting at some distance below, and more or less distinctly to the east of the point at which their junction would be effected if the tributary retained its original direction.

Wanting, or inconspicuous, in many districts, such deflected courses constitute one of the most prominent features of southwestern Berks, and south-eastern Dorset, near the western end of either basin; and it is with the larger examples in these two areas that the present paper is chiefly concerned.

In the Berkshire district (sheets 267 and 268 , new one-inch Ordnance Map) we have, firstly, the Loddon, the greater part of whose valley, below the junction of the two principal Blackwater and Basingstoke branches at Swallowfield, has a north-eastward direction, roughly parallel to that of the neighbouring KennetThames.

Next, the more marked case of the Pang, which has its origin either near Compton, on the floor of a wide transverse valley in the Berkshire Downs, or (after wet seasons) in the East Ilsley branch of that valley, further to the north-west. 'This stream at first flows south or south-eastwards, with the general dip of the Chalk, as though with the intention of joining the Kennet at Woolhampton, but on reaching Bucklebury it swings round to the eastward, and runs parallel to that river for a 
distance of about six miles, when it again turns, this time abruptly northward, and empties itself into the Upper Thames.

The Enborne, on the Berks and Hants county boundary, though less erratic, is in some respects even more interesting than the Pang, for here the deflection involves almost the entire course of the stream, giving a curiously duplicated appearance to the longitudinal drainage of this part of the London basin. Rising at, or near, the denuded crest of the Pewsey-Kingsclere anticline, below Inkpen Beacon, it flows for a few miles north-eastward, with the dip of the Tertiary rocks; then, bearing eastward, it runs for about ten miles parallel to, and at an average distance of about two miles from, the Kennet, which, by a second, north-eastward turn, it ultimately joins at Aldermaston. As a result of its prevailing eastward trend, the Enborne intercepts the bulk of the surface-drainage of the southern slope of the Kennet basin, which would otherwise be delivered directly to that river between Kintbury and Aldermaston; consequently its right-hand tributaries, if small, are numerous. On the other hand, owing to its close proximity to the Kennet throughout the greater part of its course, the Enborne receives no affuent of importance from the north: its drainage system is, therefore, singularly onesided.

In the Dorset area (sheet 328 ) the Puddle, or Trent, which has its source in the North Dorset Downs, at first runs somewhat. east of south, with the dip of the Chalk, but bears round to the east on approaching Puddletown, and thenceforward, for a distance of about fifteen miles, the larger curves of its valley follow those described by the Frome, down to the junction of the two rivers at the head of the Poole Harbour estuary.

The Empool Bottom brook, in the south of this district, is, in its beginnings, a north-easterly, dip-slope stream, but pursues a more eastward path for the greater part of its course through the Tertiary rocks south of the Frome, to which river it stands in much the same relation as the Berkshire Enborne does to the Kennet. Other examples could be named, but the above are the most important.

II.

Now the eastward deflection displayed by these affluents of the Kennet-Thames and the Frome may admit of more than one explanation, but it bears, in every case, so strong a resemblance to the down-stream turn which is frequently noticeable in the branches of a river system at, or a little below, the point where they quit their valleys for the alluvial flat, or flood-plain, bordering the trunk stream, that I have for some time felt disposed to attribute it, in a large measure, to similar causes. The phenomenon here referred to-which may be termed that of 
postponed junction-has been described by Fergusson, ${ }^{*}$ and, probably, also by other British writers, and possesses an Italian and American literature; yet, although one of the most characteristic of flood-plain features, it is seldom discussed, or even noticed, in our text-books of geology and physiography. A simple illustration is given in the accompanying diagram

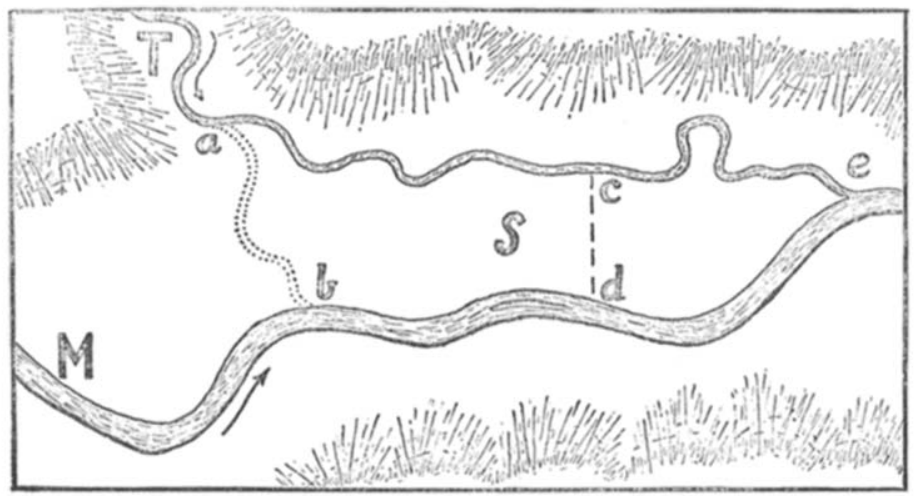

FIG. 60.

(Fig. 60), where the tributary $\mathrm{T}$, on entering the valley of the main-stream $M$, turns abruptly to the left, and flows for some distance beside, and in the same direction as, the latter river, instead of following the more direct, and what would seem to be the more natural, course suggested by the dotted lines $a$ to $b$. The deflection of the tributary in such cases is normally due to the reversing, or diverting, effect of the outward slope of the natural embankment (or levee) formed by the materials deposited along the margin of the main-stream. Being unable either to prevent the formation of this barrier across its mouth, or to build up its bed at a sufficiently rapid rate to allow of its maintaining a clear flow over the growing bank of sediment, the lesser river suffers a partial damming, and is compelled to shift its outlet, and prolong its independent course, by gradual or abrupt stages, further and further down the valley of the greater. It would seem that the conditions most favourable to this type of diversion obtain when the larger stream possesses a higher velocity, together with a much heavier burden of waste in proportion to its volume, than the smaller, and brings down to its flood-plain a significantly greater amount of material than it carries away.

Well-marked instances of postponed junction may be observed on many of the alluvial flats of south-eastern England, but for the

* "Recent Changes in the Delta of the Ganges," $Q . J . G . S ., V o l$. xix (1863), pp. 325, 342-4. 
finest examples we must turn to the flood-plains of the larger continental rivers. The plains bordering the lower course of the $\mathrm{Po}$, in northern Italy, exhibit the phenomenon in great perfection. One of the most remarkable cases-often cited by American writers-occurs on the growing flood-plain of the Mississippi, where the trunk of the complex Yazoo river system flows through the swampy bottom-land between the main river and the eastern side of the valley for a distance of about 200 miles, before effecting a junction. Prof. Davis remarks that "The Yazoo might pursue an independent course all the way to the Gulf (of Mexico), if the Mississippi did not happen at present to swing across to the bluffs on the eastern side of the flood-plain" at Vicksburg "and there take in the Yazoo"*

On instituting a closer comparison between the deflection of the above-named Berks and Dorset streams and the phenomenon of postponed junction, two points at once claim attention.

Firstly, in the typical flood-plain, the tongue-like space of ground (S, Fig. 6o) between main-stream and diverted tributary, is necessarily of such moderate elevation as to be within reach of, at least extraordinary floods, and forms a part of the floor of the valley, or "lit majeur," of the larger river; whereas, in the parallel instances under discussion, this inter-stream tract rises far above the level of the enclosing rivers at their fullest, and forms a part of the high ground in which their valleys have been excavated. Therefore, on the supposition that the Enborne, Puddle, etc., owe their eastward deflection to flood-plain diversion, it is obvious that this diversion must have been accomplished at some earlier epoch of their history, when they ran at, or above, the general level of the ground now separating their lower valleys from those of the Kennet-Thames or the Frome.

Secondly, the supposed "diversion features" of these streams differ from their analogues on the modern alluvial flats of Berks and Dorset in that they are marked out on a much bolder scale; the down-turned, or deflected, sections of the tributaries being longer, and the average distance between these sections and the main-stream much greater, than in any of the recent examples. The discrepancy is, indeed, so marked that it seems, at first sight, to render the supposed identity of origin improbable, though a little consideration will suffice to show that the difference may still be largely, if not entirely, one of degree. The length of the diverted part ( $a-e$, Fig. 6o) of a tributary, is simply an approximate measure of the amount of displacement suffered by its mouth, and, taken alone, affords no indication of the rate at which that process has been carried on. The fact that

* "Physical Geography," Boston, U.S.A., and London. Ginn \& Co. 1899, P. 287. For flood-plain features see also I. C. Russell, "Rlver Development," London, John Murray, 1898, p. 123; and Humphreys and Abbot, "The Mississippi River," I86r, chap. $1-3$. 
this down-turned part is longer in the presumed older examples of diversion than in the actual modern ones may, therefore, merely imply that the displacement was continued over a longer period in the former than in the latter. In the determination of the average distance ( $c d$, Fig. 6o), between the diverted section of such a tributary and the main stream, however, time appears to be a factor of less possible importance; and the greater breadth of the inter-stream spaces associated with the supposed older instances of diversion in south-western Berkshire and southeastern Dorsetshire seems to demand that the principal rivers of those districts (viz., the Kennet-Thames and the Frome) should formerly have possessed, not only wider flood-plains, but also greater volume, and a much higher rate of deposition, or embankment-building, than at the present day.

III.

Now the hypothesis that the deflection of the above-named streams is due to flood-plaining does not rest entirely on the strong resemblance of the one to the effects produced by the other. It finds considerable support in the physical characters of the country traversed by the lower courses of these streams; characters which more or less distinctly testify to the former prevalence of conditions analogous to those obtaining in a certain class of flood-plain over large areas of the high ground adjoining the main, longitudinal, drainage lines of the western parts of the London and Hampshire basins.

Let us first consider the evidence in connection with the very pronounced example of deflection furnished by the Enborne.

The surface of the ground drained by the Enborne and other independent southern affluents of the Kennet entering that river below Hungerford may be broadly divided, according to the characters of its prevailing slopes, into three fairly distinct zones, ranging east and west. Commencing in the south, there is, firstly, a narrow belt possessing a rapid fall in a northerly and northeasterly direction; secondly, a somewhat wider strip, of similar trend, but of more gentle inclination; and thirdly, a belt of about the same average width as the last, where the slope is very gentle and directed toward the east, and somewhat to the north of east. 'The first of these marks the outcrop of the chalk forming the range of high downs at the south-western margin of the London basin; the second and third, which expand eastwards, are underlain by Eocene rocks, frequently belonging to some part of the Bagshot series.

The third, or northern belt, which includes the greater part of the Enborne valley, is essentially one of flat-topped, more or less isolated, hills and ridges, capped with gravel, and forming open heaths, save where planted with pine. Among these tabular 
eminences there are two, which, by reason of their position and superior size, call for especial attention. These are $(a)$ the long

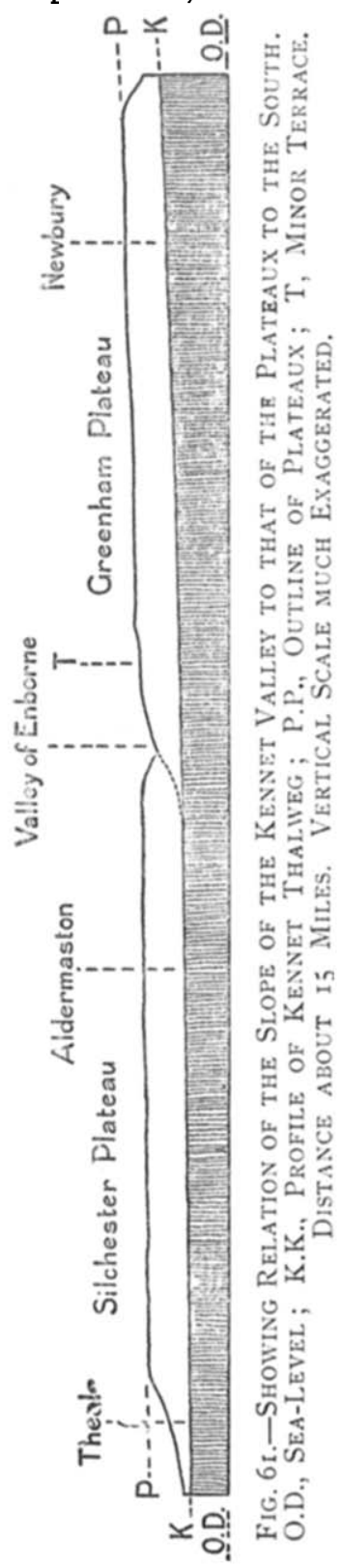
ridge of Wash, Greenham, and Crookham Commons, between the parallel valleys of the Kennet and the Enborne: and $(b)$ the wider tract of moderately high ground supporting the commons of Brimpton, Tadley, Silchester, and Burghfield, to the east and south-east of the junction of those streams. When viewed from certain points on the northern side of the Kennet Valley these eminences - henceforward referred to as the Greenham and Silchester plateaux ${ }^{*}$-combine to form a striking terrace-like feature in the landscape, in marked contrast to the more uneven ground rising beyond to the foot of the boldly-undulating uplands of Sydmonton and Inkpen. Now, the prevailing slope of the ground in this northern belt being toward the east, as above noted, the crest, or upper surface, of each of these plateaux is distinctly higher at its western than at its eastern end, while the inclination of the Greenham flat (from 4 I I to 372 feet O.D.), on the left bank of the Enborne, is continued in the Silchester flat (from 35 I to 3 I 4 feet O.D.) on the right bank of that stream. But this slope, which steadily decreases from about io feet per mile on Greenham Common, down to about 6 feet per mile on Burghfield Common, agrees so closely with that of the thalweg of the parallel section of the Kennet, that the crests of the plateaux maintain a fairly constant elevation of about i6o feet above the modern alluvium of that river between Newbury and 'Theale. The longitudinal profiles of the two slopes are, in fact, nearly parallel curves of the upwardly concave form roughly represented in Fig. 61.

The stream-wrought origin of the

* "Silchester plateau"; so named by Mr. H. W. Monckton, Quart. Journ. Geol. Soc., vol. xlix, p. 3 IO. 
surface of these plateaux, so strongly suggested by this coincidence, is fully confirmed by the underlying drift-beds, which present all the features common to the coarser kind of river deposits. The high-level drifts forming the widely-represented class known as "Plateau Gravel," to which these beds belong, are now, indeed, very generally admitted to be of fluviatile origin, and a large body of evidence is available in support of the view that they were laid down by the representatives of existing streams, during an earlier period in the topographical history of the regions in which they occur.

The Plateau Gravel in the neighbourhood of Newbury having been described in our Proceenings and elsewhere, ${ }^{*}$ it will suffice to state that it consists mainly of subangular flints, with a variable proportion of flint-pebbles, and of more or less worn fragments of sarsen-stone, in a matrix of sand or loam; frequently exhibits strung current-bedding, with rapid changes of texture; and appears to attain its maximum thickness, of about 20 feet, under Wash Common, near the western end of the Greenham Plateau.

Possessing a wide range in elevation within comparatively restricted areas, its several sheets are clearly not the product of a single age. Nor are they logically separable, as a group, from the gravel terraces of the valleys, into which they occasionally merge. They are rather to be regarded-as Mr. Moncktont has recently urged in the case of their representatives in the adjoining Bagshot district-as the older, and usually more strongly developed, members of a graduated succession of deposits, of similar character and habit, ranging downwards through the terraces of River Drift, to the Valley Gravels at, or but little above, the level of the recent alluvium.

The task of correlating such stair-like deposits is rarely unattended by grave difficulties. Their vertical frequency, their lateral discontinuity, the gradation of older into newer, our ignorance of the gradients of their responsible streams at the time of their formation; all these circumstances are prejudicial to the satisfactory identification of contemporaneous sheets, even within the limits of so small a basin as the Kennet's. Still, among the many gravel-flats and terraces of the Newbury district it is possible to trace a few well-defined stages, of which that including the beds on the Greenham and Silchester plateaux is by far the most marked. The dimensions of these plateaux, particularly the (north to south) width of the second, alone suffice to show that this stage was one of considerable importance in the history of the Kennet basin. Yet these two gravel sheets are but * Eristow and Whitaker, Geol, Surv. Menoir, on Sheet I2 (1852), pp. $38,43,44 ;$
Prestwich, Quart. Journ. Geol. Soc, vol. xlvi (189o), pp. 16r-2; Monckton, Quart. Journ. Geol. Soc, vol. xiviii (1892), pp. 39, 40; vol. xlix (1893), p. 3 ro; vol. liv (1893), p. IgI. Richards, Quart. Journ. Geol. Soc., vol. liil (1891), pp. $220-1$. Blake, Proc. Geol. A ssoc., vol. xvi (1900), p. 513 .

+ "Origin of theGravel Flats of Surrey and Barkshird," Geol. Mag., New Series, Dec. iv, vol. viii (1901), F. 51 I. 
remnants of a far more extensive spread, that seems to have involved the whole of the area of moderately accidented country roughly defined by the Hungerford, Reading, and Aldershot triangle. It is interesting to notice that while no part of the ground within this area attains an elevation significantly greater than 160 feet above the level of the nearer of the two principal streams (viz., the Kennet and the Blackwater-Loddon) at its nearest point, this height limit is reached, or closely approached, by many large gravel plateaux-including those of Greenham, Bradfield, Silchester, Hartford Bridge Flats, and Finchampstead Ridges - and by a number of well-defined terraces bordering the higher ground on the north, south, and east. The coincidence may be an accidental one, but when taken in connection with the general centripetal trend and inclination of the above-named plateaux, it certainly suggests that the existing relief of this area has been carved out of a drift-mantled plain of subaërial erosion, whose gentle slopes converged, like the sides of a shallow funnel, towards a point somewhere in the vicinity of the site of Reading.

But whatever the original extent of the great gravel-sheet of (what may be termed) the "Silchester" stage, the relics in the neighbourhood of Newbury plainly indicate, (I) that when the effective base-level of erosion of the district stood about I 50 feet higher than at present, it remained practically stationary for so long a time that a broad and shallow vale, or "bottom," was opened out in the weak Tertiary beds along the main-line of drainage; and (2) that the surface of this depression was strewn with a mass of stream-borne waste, derived from the surrounding slopes. The formation of this vale is, doubtless, to be ascribed (like that of the existing Kennet Valley) in a large measure, to the lateral corrasion of the streams responsible for the drift covering its floor; though the considerable width of the reduced area-not less than six miles in the longitude of Newbury, and the gradual manner in which many of the outlying terraces forming the relics of its marginal portions merge into the steeper slopes of the enclosing high ground, convey the impression that the bulk of the work of planation was performed by the relatively slow process of subaërial degradation.

It is possible that the spreading-out of the gravel proceeded pari passu with planation; the area of deposition slowly expanding as the floor of the valley gained in width, and more and more ground was brought within reach of the streams; but there are indications that the drift which has been preserved to us on the plateau and terraces of the Silchester stage was laid down when the work of reduction was practically completed, and by streams of small erosive power. Evidence of this is seen in the westward, or up-stream, thickening of the deposits on the larger plateaux, near the median line of the old valley, and also, perhaps, in the distinct, obliquely-transverse slope 
away from the Kennet which is noticeable in the surface of the Greenham plateau; the former pointing to an aggradation (or increase of gradient by deposition), the latter to an embanking of the main river-and therefore also of its tributaries-such as one associates with streams of constructive, rather than with those of destructive, tendencies.

The gravel appears, in fact, to date from near the close of the Silchester age, when, owing to some change-presumably of a climatic nature-the main-stream and the tributaries entering it below Hungerford could no longer transport the material they acquired in their upper courses down the gertle slopes of their lower courses through the Tertiary lowland, and were compelled to employ a portion of their load in raising the gradient of their beds, and in partially filling-up the wide depression they had previously helped to produce. The greater part of the excess of rock-waste seems to have been deposited in the form either of broad stream-embankments of low profile along the axis of this depression, or of confluent fans, sloping inwards from its margin. To judge from the internal structure and the composition of the gravel, the overloading of these streams was occasioned, not by any diminution of their volume, but by the more rapid supply of débris-the bulk of which was derived from the Chalk, or more probably from the flinty soil overflowing that rock on the higher slopes of the basin-arising from an increase in the rate of denudation.

With regard to the size of the principal, west-to-east, river of the district at this time, it may be noted that although this river had long ceased to deepen its valley, and (so far as one can judge by the slope of the larger plateaux)* was spreading out its gravel at about the same inclination as that of the recent alluvium of the existing, approximately-graded Kennet, it by no means follows that its volume was not appreciably greater than that of the latter stream. It has often been stated-sometimes without any qualification - that the angle of slope at which a river ceases to lower its channel varies inversely as the volume of water, or, in other words, that the larger the river the gentler is its "final" slope. This angle, however, depends not merely on the volume of the stream, but also on the mass and texture of the débris which it has to transport; and a smaller river with a light load of fine material may have a profile of equilibrium with gradients appropriate to that of a larger one with a heavy burden of coarse detritus.t In view of the distribution, internal structure, and generally coarse character of the deposits on the plateaux and

\footnotetext{
"The (mainly elevatory) earth movements affecting this district in post "Silchester" times do not appear to have produced any sensible amount of deformation.

+ See W. M. Davis, op. cit., p. 243. Also, "Physical Geography in the University," Joum. Geol., vol. ii (1894), p. 78; and " Baselevel, Grade, and Peniplain," ibid., vol. $x$ (1902) pp. 77-IIr. The last-named article, of whose existence I was not aware until after the reading of the present paper, is one that should be consulted by all who are interested in the
life histories of rivers and land-torns.
} 
terraces of the Silchester stage, it is highly probable that the Kennet was then both swifter and larger than at the present day, but so much more heavily loaded with gravel as to be incapable of carrying on the work of transportation with a distinctly lower gradient. The former greater volume of the Kennet is also to be inferred from the loss of drainage area it has suffered, and is still suffering, by the encroachment of the Salisbury and Bristol Avons, and of the subsequent branches of the upper Thames to the north of Berkshire and Marlborough Downs.* The amount of shrinkage due to this cause since the date here referred to, however, is probably trifling as compared with that arising from lessened precipitation.

From the foregoing remarks it may be gathered that the even and gently-inclined surface of the ground enclosing the valley of the Enborne, and separating it from that of the Kennet, is not only the work of fluviatile agencies, but a resuit of the two distinct processes of planation and aggradation responsible for a large class of flood-plains. The drift beds underlying this surface differ, it is true, from those found in the modern flood-plains of the south-east of England, in consisting almost entirely of gravel, but there is no reason to doubt that they belong to the same order of fluviatile deposits.

The conditions under which these beds were laid down were of a kind particularly favourable to stream diversion of the " postponed junction" type, and although it cannot positively be asserted that these conditions were responsible for the eastward deflection of the Enborne, the fact that the greater part of the valley of that stream has been carved out of the floor over which they prevailed certainly tends to confirm this view. Indeed, the Enborne appears to owe, not only its direction, but its very existence as a hydrographical unit to the damming and downstream turning influence which the overburdened Kennet brought to bear upon a group of small, southern, tributaries towards the close of the Silchester stage.

\section{IV.}

Similar evidence is forthcoming in the case of each of the other deflected rivers mentioned in the beginning of this paper. In every instance the ground enclosing the defiected part of the tributary, or serving as a barrier between it and the main stream, is, in a large measure, overspread with sub-angular gravel of fluviatile origin, forming more or less well-defined plateaux, with a prevailing slope in the direction pursued by the latter river. Where the individual plateaux are sufficiently large, or sufficiently close together, to enable one to distinguish their purely local

- Auct. cit. Geosraphical Journal, vol, v (1895), No. 2, pp. 144-5. See also, S. S. Buckman Nat. Sci., vol. xiv (1899), No. 86, p. 282; and Proc. Cottestoold, Nat. Field Club, vol. xiii (Igoo), pp. I37-9. 
slopes, due to irregularities of constructional or destructional origin, from their general gradients, the latter are commonly found to approximate fairly closely to those of larger neighbouring

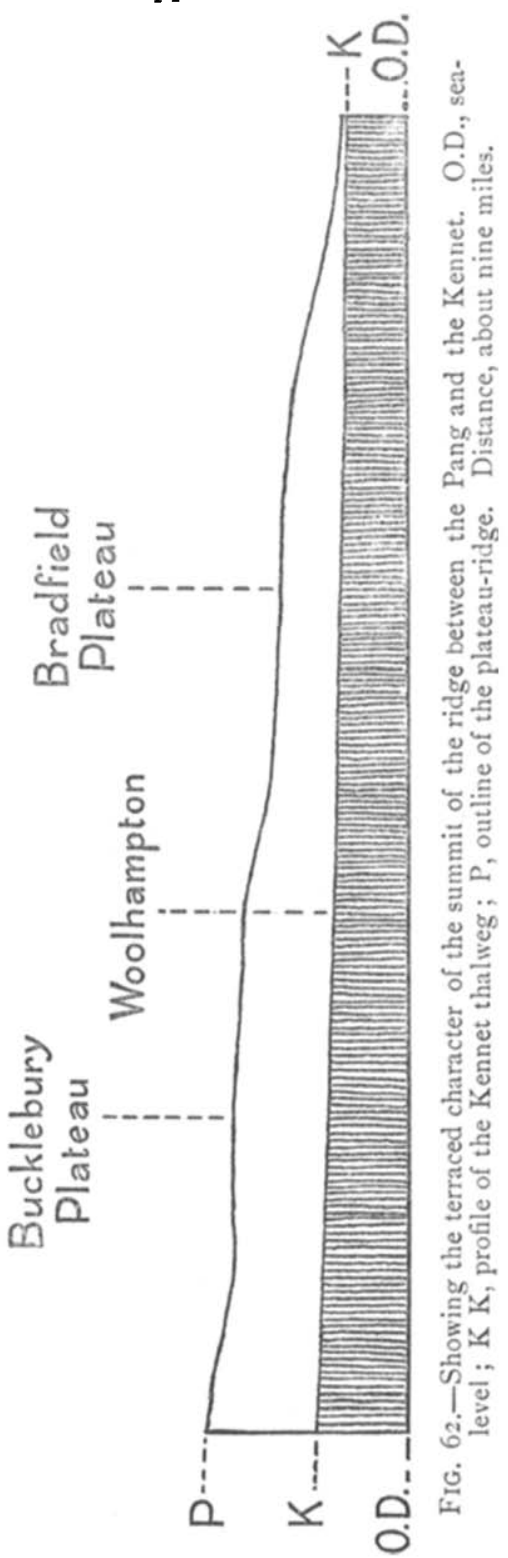
valleys.

There is, however, an im. portant feature of the driftcovered country bordering the lower courses of these rivers to which no reference has as yet been made, viz., the composite form of the crest, or upper surface, of the ground intervening between deflected tributary and main-stream. Close observation is rarely needed to apprise one of the fact that the continuity of the longitudinal crest slope of such inter-stream tracts is broken by two, three, or more tolerably distinct terraces, of which the lower lie nearer to, and the higher more remote from, the point of junction of the two streams. The larger terraces, which are generally among the higher of the series, are almost always represented at similar or appropriate levels in the surrounding district by other terraces, or plateaux, marking important stages in the development of the existing topography. It not infrequently happens that the greater part of the whole available area of the summit is occupied by some one member of the stair-like succession; the Greenbam Common ridge, between the Kennet and the Enborne, where the predominance of the highest terrace gives the whole feature the 
aspect of a single plateau, being an extreme instance of this kind.

The composite character of the inter-stream surface is well shown in the high ridge separating the Kennet from the Pang, part of whose outline is indicated in Fig. 62, P. The less inclined sections of this line mark the position of two gravel flats; the higher underlying Bucklebury Common, the lower, which is much dissected, supporting Bradfield Common and South End, and forming the top of the spur running north-east from Beenham. The Bucklebury plateau has a gently undulating surface, and is probably of more than one age, though no clear line of demarcation can be drawn between its constituent parts, but the break between it and the Bradfield flats, which belong to the Silchester stage, is marked by a disappearance of the drift, and by an increase of slope very perceptible in the field.

The long, stony, heath-covered tract, between the Dorset Puddle and the Frome, exhibits a yet more broken character.

Now, these stair-like inter-stream tracts bear so obvious a resemblance to the complex "junction terraces" described by Miller, that it is difficult to resist the conclusion that they have a very similar origin, and that their constituent flats mark, approximately, the successive portions of the confluence of the streams on either side. In the majority of the examples here referred to the enclosing rivers drain the same kinds of rock, and their alluvia being therefore indistinguishable, it is impossible to determine whether these terraces belong to one alone or to both. In the drift deposits between the valleys of the Lower Loddon and the Thames, however, both rivers are clearly represented, and Mr. Monckton t has noted the lateral passage of the cherty gravel of the former into the quartzite gravel of the latter, near the morthern end of the Sonning-Earley plateau, some three miles to the south-west of, and above, the present junction of these streams.

While, then, the surface-form of these interstream areas tends to confirm the view expressed in this paper with regard to the significance of the deflection of above-mentioned tributaries of the Kennet-Thames and the Frome, it also serves to show that this deflection is the product of more than one, and perhaps of many, ages. Thus, the diversion of the once independent affluents of the Kennet now forming the Enborne appears to have been effected at the Silchester stage, but the presence of a minor terrace (marked 'T, Fig. 6I) at the easterm end of the Greenham plateau, suggests that the Enborne itself received a slight accession to its length at a somewhat later time. Much of the lower course of the Pang also dates from the Silchester stage, but here diversion clearly began earlier, for the Bucklebury plateau, on the higher " "River Terracing," Proc. Roy. Ph. Soc., Edinburgh, vol. vii (188I-3), pp. 287-8.
+Quart. Joum. Geol. Soc., vol. xlix (1893), p. 3I2. 
part of the ridge, between this stream and the Kennet, rises about 60 or $70 \mathrm{ft}$. above that datum.

The course of the Loddon below Swallowfield is a growth of many stages, all, apparently, of post-Silchester date.

In the Dorset area, the displacement of the mouth of the Puddle was probably accomplished mainly during the epoch of the local "Older Plateau Gravel" of Puddletown Heath, Affpuddle Heath, and Stokeford Heath, on the relatively high ground between that stream and the Frome: further developments, however, took place during the deposition of the "Newer Plateau Gravel" covering the lower step of Stokeford Heath, near the eastern end of this inter-stream area, ${ }^{*}$ and at still later stages, down to the level of the modern marsh-land.

The Empool Bottom brook seems, like the Enborne, to have resulted from the obstruction, and consequent combination in a single trunk, of a group of small, north-eastward, streams tributary to the Frome; the diversion in this case dating from the time of the Newer Plateau gravel.

The prevalence of deflected streams near the western end of both the London and Hampshire basins, which was referred to at the commencement of this paper, shows that the conditions there have been exceptionally favourable to diversion. The reasons for this are not very apparent, but a possible explanation is to be found in the closing-in of the synclinal folds determining these basins, whereby the marginal uplands of comparatively resistant Chalk occur in close proximity to the main, longitudinal, lines of drainage established on the tongues of easily reduced Tertiary rocks in the bottom of the troughs. With a more abundant aqueous precipitation, and a higher rate of denudation, such as have, at times, undoubtedly prevailed in the past, the steep Chalk slopes ensured by this conjunction would yield a rapid supply of coarse débris immediately to the principal water-ways, thus placing them, locally, in the heavily burdened condition in which they would be most likely to divert their tributaries in these districts.

V.

The deflected parts of all the streams so far dealt with are restricted to somewhat narrow zones bordering the Kennet-Thames or the Frome, where the relatively high rate of erosion and the weakness of the rocks have been especially conducive to the development of open valleys and wide flood plains during the more prolonged of the numerous pauses which have interrupted the (generally) negative, or downward, displacement of the baselevel of southern England. 1 propose to conclude this paper with a brief notice of an interesting little example of postponed

-C. Reid. "Geology of the Country around Dorchester. Mem. Geol. Surv., 1899, pp. 40-42. 
junction connected with a southern affluent of the lower Frome, but situated at some distance from, and not attributable to, the influence of the latter river.

This occurs in the Isle of Purbeck (Sheet 343, one-inch Ordnance Map, New Series Geological), where the eastern and western branches of the Corfe River, flowing inward from near either end of the longitudinal valley which marks the outcrop of the Wealden Beds, turn northward on approaching one another at Corfe, and traverse the Chalk ridge in sharply cut gorges, separated only by the narrow and precipitous Castle Hill, ere they unite, at the margin of the Eocene Beds. (Fig. 63.)

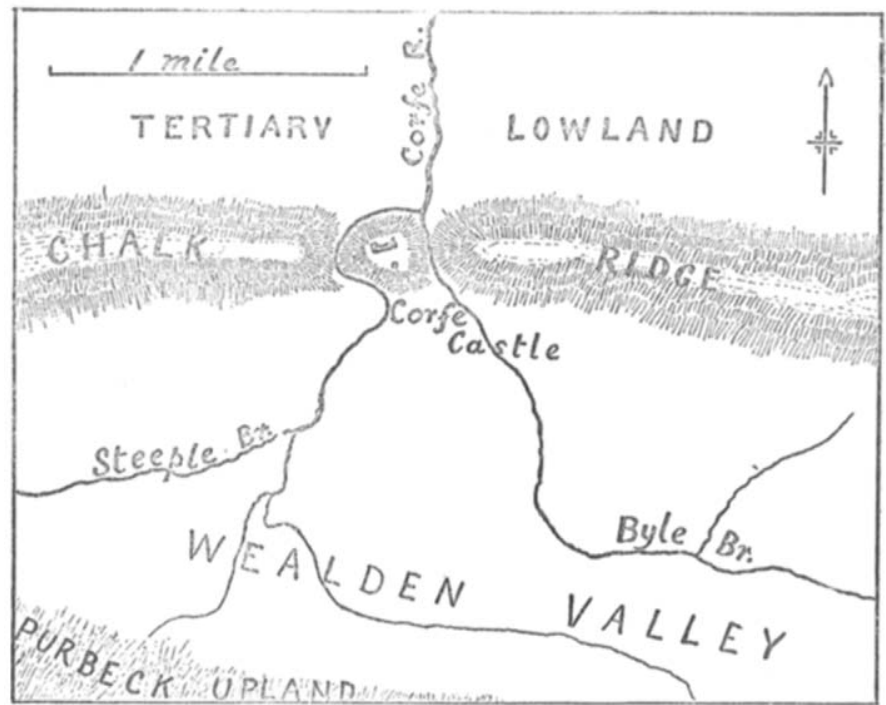

Fig. 63.-Sketch Map of the Vicinity of Corfe Castle, Isle OF PURBECK.

The generally accepted explanation of this curious double breach in the Chalk appears to be that offered by Mr. Strahan,* who-if I rightly understand his somewhat brief remarksconsiders it to have been initiated by a pair of streams engendered on the northern slope of the Purbeck anticline, at a time when the arch of the fold was unbroken, and its drainage still essentially of the consequent order. But while there is no reason to doubt that, from a very early stage in the physiographical development of the district, an appreciable fraction of the drainage of the Purbeck anticline has passed transversely over, or through, the existing Chalk ridge in the near vicinity of the site of Corfe Castle, it may none the less be questioned whether 
the dual manner in which its passage is at present effected can boast of nearly so high an antiquity.

The chief objection to this view arises from the arrangement, and the great difference in the powers of resistance, of the rocks exposed by denudation in the southern part of the Isle. The outcrop of the yielding clays and sands of the Wealden Series, interposed, as it is, between that of the more durable Purbeck limestones and that of the locally indurated Chalk, has long formed a peculiariy favourable field for stream adjustment, as may be seen by the well-marked subsequent character of its drainage; and it seems quite improbable that two streams engaged in cutting down their channels through this belt of weak rocks, and through the succeeding sill of hard Chalk, in such close proximity, could have preserved their independence for so long a period as that implied in the above hypothesis. Unless their rates of vertical corrasion in the controlling stratum (i.e., the Chalk) were balanced to a remarkable degree of nicety, one or the other of these streams would surely have gained sufficient advantage to enable it to decapitate its neighbour on the south side of the Chalk ridge, long ere this.

It is true that the western, or Steeple Brook, * branch of the Corfe River has acquired a large share of the drainage area of the eastern, or Byle Brook branch, and seems destined, by the aid of the encroaching Swanage stream, to reduce the eastern breach in the chalk ridge to the condition of a wind-gap; but when regarded as the outcome of a life-long struggle, its gain so far is pitifully insignificant.

A decidedly more probable view is that recently brought forward by Mr. W. H. Hudleston, $\uparrow$ viz, that the eastern and western branches of the Corfe formerly united on the south side of the Chalk outcrop, and traversed it by a single channel; and that when this channel had been cut down to about the level of the summit of the Castle Hill (about $170 \mathrm{ft}$. below the ridge on either side), the two streams became separated, and commenced to carve out independent gorges.

Mr. Hudleston offers no suggestion as to the cause of the separation of these streams, but a northerly displacement of their junction, under flood-plain conditions, during a temporary cessation of the down-cutting process, seems by far the most natural explanation.

There are indications that the Byle Brook, though now the smaller, played the part of main-stream, or divertor, in this change. If this was actually the case, then the western gap must be regarded as an accidental feature, due to the local superimposition of the diverted longitudinal Steeple Brook upon the Chalk, from the alluvium covering the floor of the original, single, transverse valley.

"Also known as the Wicken Brook.

Proc. Geol. Assoc, Vol. XVI1, Parts g \& 10, AUg. \& Nov.. 19:3:] 